\title{
Feasibility of patient-collected vulval swabs for the diagnosis of Chlamydia trachomatis in a family planning clinic: A pilot study
}

\author{
Susan Macmillan, MRCOG, DFFP, Clinical Research Fellow, Department of Obstetrics and Gynaecology; Hamish \\ McKenzie, BSc, MB ChB, PhD, FRCPath, Senior Lecturer and Honorary Consultant, Department of Medical Microbiology, \\ University of Aberdeen, Aberdeen, Scotland
}

Gillian Flett, FRCOG, MFFP, Consultant in Family Planning and Reproductive Health Family Planning Services, Grampian Healthcare NHS Trust, Aberdeen, Scotland

Allan Templeton, MD, FRCOG, Professor, Department of Obstetrics and Gynaecology, University of Aberdeen, Aberdeen,
Scotland

Correspondence: Dr Susan Macmillan, Clinical Research Fellow, Department of Obstetrics and Gynaecology, Aberdeen Maternity Hospital, Foresterhill, Aberdeen AB25 2ZD, Scotland

(Accepted June 12 $2^{\text {th }}, 2000$ )

\begin{abstract}
Summary
This pilot study set out to determine the feasibility of using patient-collected vulval swabs, instead of urine, for the diagnosis of female Chlamydia trachomatis infection. Main outcome measures included prevalence of infection and sensitivity, specificity, and acceptability of both test methods. An assessment was also made of those who declined to be tested. Consecutive women under 25 years of age attending a single urban family planning clinic were invited to participate. Sixty-eight percent (103/152) agreed to undergo testing. Overall prevalence was $11.7 \%$. The sensitivity/specificity for the ligase chain reaction (LCR) assayed patient-collected vulval swabs and urine was $100 \% / 100 \%$ and $92 \% / 100 \%$, respectively. The acceptability of self-collection was high with $93 \%$ characterising the test as 'not bad', 79\% recommending it to a friend, and 79\% choosing the test next time. Significantly more women, however, would choose urine for testing on a subsequent occasion $(p<0.001)$. Less than $1 / 5$ of the patients who declined did not take part because of concerns regarding the vulval swab. Patient-collected vulval swabs assayed by $L C R$ represent a non-invasive, sensitive, and acceptable way to detect genital $\mathrm{C}$. trachomatis infection in women attending a family planning clinic. Compared with urine testing, benefits in terms of transport and processing should encourage more widespread use of this approach.
\end{abstract}

\section{Key words}

acceptability, Chlamydia trachomatis, ligase chain reaction, patient-collection, vulval swabs

\section{Introduction}

Chlamydia trachomatis is the most common sexually transmitted infection in the United Kingdom (UK). Most female infections are asymptomatic and consequences include pelvic inflammatory disease, ${ }^{1,2}$ tubal infertility, 3,4 and ectopic pregnancy. ${ }^{5}$ Infection risks are highest in women under 25 years of age $\mathrm{e}^{6,7}$ and complications may be more severe. ${ }^{8-9}$ In response, the CMO's Expert Advisory Group on Chlamydia ${ }^{6}$ has recommended opportunistic screening, targeting asymptomatic, sexually active women under 25 years of age, especially teenagers. There is a need now to increase the uptake and acceptability of testing.

Despite a clear case made for screening, the optimum diagnostic test to satisfy both patients and health care professionals is still not known. Until recently, accurate

\section{Key message points}

- C. trachomatis is the most common sexually transmitted bacterial infection in the UK. While most female infections are asymptomatic, the risk of acquiring the infection is related to young age and complications may be more severe in younger women.

- The CMO's Expert Advisory Group on Chlamydia has recommended opportunistic screening, targeting asymptomatic, sexually active women under 25 years of age, especially teenagers.

- Nucleic acid amplification tests are highly sensitive and specific and have the ability to test non-invasively using either urine or vulval swabs.

Most recent studies have focused largely on urine testing, despite concerns regarding provision of samples, inhibitors, and transport issues. Vulval swabs, particularly when patient-collected, may be a better alternative.

- This study found that patient-collected vulval swabs assayed by LCR represent a non-invasive, sensitive, and acceptable way to detect genital chlamydial infection and more widespread use should be encouraged.

diagnosis of genital $C$. trachomatis infection could be achieved only by invasive collection, and in the UK the majority of women still undergo endocervical testing using enzyme immunoassay (EIA). With advances in DNA technology, however, nucleic acid amplification assays have been introduced. Advantages include high sensitivity and specificity, and the ability to test non-invasively using either urine ${ }^{10}$ or vulval swabs. ${ }^{11}$

Most recent studies have focused largely on urine testing. Despite advantages in terms of familiarity and noninvasiveness, disadvantages include the inability to produce a sample on demand. One study ${ }^{12}$ found that $25 \%$ of the participants were unable to produce a urine specimen. There also exist concerns regarding inhibitors, ${ }^{13}$ transport issues relating to bulkiness and refrigeration, ${ }^{14-16}$ and the need for additional laboratory processing steps. In contrast, vulval swabs can be performed on demand, are compact, do not appear to be as susceptible to temperature influences, and require fewer processing steps. Furthermore, patientcollected swabs have the potential to decrease both patient embarrassment and clinic costs.

The aims of this study were to determine the feasibility, in terms of sensitivity and acceptability, of using LCR assayed patient-collected vulval swabs, instead of urine, for the diagnosis of female genital $C$. trachomatis infection in a family planning population. Assessment of those who declined to undergo screening was also undertaken. 


\section{Method}

All screening was undertaken at Square 13, a single urban family planning clinic. Consecutive women under 25 years of age, were invited to participate in the study by means of an information sheet. Antibiotic use in the previous month and symptoms of pelvic infection were the exclusion criteria. Approval for the study was received from the local Ethical Committee.

\section{Study population}

One hundred and three apparently healthy women were recruited during January to May 1998.

\section{Specimen collection}

Instructed not to clean their vulval region prior to sampling, the women collected the samples in one of the clinic's toilets. Advice regarding vulval swabbing was given both verbally and pictorially (Figure1). The vulval swab was collected by rotating the swab $0.5 \mathrm{~cm}$ within the vaginal introitus, against the posterior fourchette. Approximately $20 \mathrm{ml}$ of first void urine was then collected in a universal container. Specimens were either transported directly to the microbiology lab, or were refrigerated overnight for collection the following day. As the clinic is off-site from the main laboratories, specimens were transported for approximately 2 hours un-refrigerated.

\section{Specimen testing}

The LCR assays were performed by a dedicated technician with the LCx probe system (Abbott Diagnostics, Maidenhead, UK) in accordance with manufacturer's instructions.

\section{Resolution of LCR discrepancies}

Any set of patient specimens was considered discrepant if the two test results were not unanimous. All initially positive specimens were re-tested by LCR for both samples. In those women whose paired results remained discrepant, confirmation testing of the positive LCR sample was performed by sending the specimen to Abbott Laboratories, Abbott Park, Illinois, USA for assay by LCR of a target sequence in the gene coding for the major outer membrane protein (MOMP). This was done in a blind fashion with

Figure 1 How to do a vulval swab

Note: You can use a mirror if you like.
The swab is taken from the area where you
insert a tampon.
Instructions
Open the swab packaging from the top, away
from the cotton swab ends.
Take out the thinner swab without touching the
cotton end.
Hold the swab at the non-cotton end.
Place the cotton end just inside the
vaginal opening against the vaginal wall.
Twirl the swab six times and wait
5 seconds.
Remove the swab without the cotton end
touching the rest of your body.
Keep the swab in your hand.
Take the brown cap off the container
without spilling the fluid inside.
Insert the swab into the container, cotton end
Give the container to your nurse/doctor.

coded samples. Known negative samples were also included.

Analysis

For calculation of test performance, a woman was considered to be truly positive if both specimens were positive, or if the positive specimen in a discrepant pair was confirmed by LCR MOMP. Uninfected patients were defined as those with negative LCR tests for both the vulval and urine specimens. False positive results were defined as positive results that were not confirmed on re-testing, and discrepant positive LCR results that could not be confirmed by LCR MOMP. Following resolution of discrepant results, the sensitivity, specificity, and predictive values (positive and negative) for each specimen was calculated, as described by Griner et al. ${ }^{17}$

\section{Acceptability}

Following testing, participants were asked, by semistructured interview, questions relating to acceptability of both test methods. Answers were recorded on a data sheet along with basic demographics.

\section{Decliners}

By semi-structured interview, basic demographics and the reason for declining to participate was recorded.

\section{Statistics}

Data were stored in a personal computer and the results were analysed using the Statistical Package for Social Services (SPSS). Characteristics of the participants and decliners were compared using Chi-square statistic with Yates' continuity correction or Fisher's exact test where greater than $25 \%$ of the expected cells were less than five. For calculation purposes, appropriate groups with small or no representation were combined or the group was omitted. Chi-square statistic with Yates' continuity correction was used to compare vulval and urine testing in terms of acceptability. $\mathrm{P}<0.05$ was considered statistically significant.

\section{Results}

A total of 103 women under 25 years of age were tested for C. trachomatis infection by LCR assay of vulval swabs and first void urine. Mean age was 19.9 (SD 2.6) years with a range from 14 to 25 years. Sixty-eight percent (103/152) of those approached agreed to participate in this study. Those declining were no different from those accepting in relation to age, marital status, parity, occupation, reason for visit, and contraceptive use (Table 1). Table 2 states the main reasons given by the decliners for not participating. More than one reason was given in some cases.

Specimens from 91 participants tested negative by both tests, and these women were considered uninfected. Eleven participants tested positive by both tests and were considered infected. One woman tested positive by vulval swab but negative by urine. This was confirmed on retesting of both samples by LCR. The vulval swab was subsequently confirmed positive by LCR MOMP assay. On the basis of our definition of an infected woman, 12 of the 103 women were infected with $C$. trachomatis, resulting in a prevalence of $11.7 \%$. Of the 12 infected women, 11 $(91.7 \%)$ were positive by LCR of FVU and all (100\%) by vulval LCR. The sensitivity, specificity, and predictive values (positive and negative) of the vulval swabs were $100 \%, 100 \%, 100 \%$, and $100 \%$, respectively. The sensitivity, specificity, and predictive values (positive and negative) of urine were $91.7 \%, 100 \%, 100 \%$, and $98.9 \%$, respectively. 
Table 1 Patient characteristics of the study participants $(n=103)$ and decliners $(n=49)$

\begin{tabular}{llll}
\hline Characteristic & $\begin{array}{l}\text { Participants } \\
\mathrm{n}(\%)\end{array}$ & $\begin{array}{l}\text { Decliners } \\
\mathrm{n}(\%)\end{array}$ & $\begin{array}{l}\text { P value } \\
(95 \% \text { confidence } \\
\text { interval })\end{array}$ \\
\hline Mean age (SD) & $19.88(2.6)$ & $19.8(2.82)$ & $\begin{array}{l}0.863^{1} \\
(-0.997 \text { to } 0.836)\end{array}$
\end{tabular}

Marital status:

\begin{tabular}{|c|c|c|c|}
\hline $\begin{array}{l}\text { Single } \\
\text { Married or cohabiting }\end{array}$ & $\begin{array}{l}81(78.6) \\
22(21.4)\end{array}$ & $\begin{array}{l}38(77.6) \\
11(22.4)\end{array}$ & $0.879^{2}$ \\
\hline $\begin{array}{l}\text { Parity: } \\
\text { Nulliparous } \\
\text { Parous }\end{array}$ & $\begin{array}{c}100(97.1) \\
3(2.9)\end{array}$ & $\begin{array}{c}47(95.9) \\
2(4.1)\end{array}$ & $0.658^{3}$ \\
\hline $\begin{array}{l}\text { Occupation:* } \\
\text { Professional / } \mathrm{Mgnt}^{4} \\
\text { Skilled } \\
\text { Semi-skilled } \\
\text { Unskilled } \\
\text { Student } \\
\text { Housewife } \\
\text { Unemployed }\end{array}$ & $\begin{aligned} 8 & (7.8) \\
13 & (12.6) \\
22 & (21.4) \\
5 & (4.9) \\
50 & (48.5) \\
2 & (1.9) \\
3 & (2.9)\end{aligned}$ & $\begin{aligned} &(4.1) \\
& 4(8.2) \\
& 8(16.3) \\
& 2(4.1) \\
& 32(65.3) \\
& 1(2.0) \\
& 0\end{aligned}$ & $0.186^{2}$ \\
\hline $\begin{array}{l}\text { Reason for visit:** } \\
\text { First visit } \\
\text { Repeat prescription } \\
\text { Emer contraception } \\
\text { Advice } \\
\text { Smear/IUCD } \\
\text { Pregnancy test }\end{array}$ & $\begin{aligned} 4 & (3.9) \\
53 & (51.5) \\
30 & (29.1) \\
8 & (7.8) \\
2 & (1.9) \\
6 & (5.8)\end{aligned}$ & $\begin{array}{l}0 \\
33(67.3) \\
12(24.5) \\
3(6.1) \\
0 \\
0\end{array}$ & $0.372^{2}$ \\
\hline $\begin{array}{l}\text { Contraception:*** } \\
\text { None } \\
\text { COCP } \\
\text { Condom } \\
\text { Double Dutch } \\
\text { POP } \\
\text { Depo } \\
\text { Cap }\end{array}$ & $\begin{aligned} 3 & (2.9) \\
45 & (43.7) \\
37 & (35.9) \\
5 & (4.9) \\
1 & (1.0) \\
11 & (10.7) \\
1 & (1.0)\end{aligned}$ & $\begin{array}{l}1(2.0) \\
30(61.2) \\
11(22.4) \\
2(4.1) \\
0 \\
4(8.2) \\
1(2.0)\end{array}$ & $0.161^{2}$ \\
\hline \multicolumn{4}{|c|}{$\begin{array}{l}* \text { For calculation purposes, groups } 1 \text { and } 2 \text {, and } 3 \text { and } 4 \text { were combined. } \\
\text { Groups } 6 \text { and } 7 \text { were omitted. } \\
* * \text { For calculation purposes, only groups } 2 \text { and } 3 \text { were compared. } \\
* * * \text { For calculation purposes, groups } 2 \text { and } 4,3 \text { and } 7 \text {, and } 5 \text { and } 6 \text { were } \\
\text { combined. Group } 1 \text { was omitted. } \\
{ }^{1} \text { Student t-test } \\
{ }^{2} \text { Chi-square statistic with Yates' continuity correction } \\
{ }^{3} \text { Fisher's exact test } \\
{ }^{5} \text { Professional or management } \\
{ }^{6} \text { Emergency contraception }\end{array}$} \\
\hline
\end{tabular}

With regard to acceptability, the women were asked how they found the tests- 'not too bad' or 'didn't like it'. Both tests were highly acceptable with only $6.8 \%(7 / 103)$ and $1.9 \%(2 / 103)$ stating they didn't like the vulval swabs or urine tests, respectively. This was not significantly different $(p=0.17)$. The women were then asked whether, if a female relative or friend was being offered the tests, which, if any, would they recommend. The vulval swab was recommended by $10.7 \%(11 / 103)$, urine by $21.4 \%(22 / 103)$, and both by $68 \%(70 / 103)$. Combining these found the vulval swab recommended by $78.6 \%(81 / 103)$ and urine by $89.3 \%(92 / 103)$. These were not significantly different $(p=0.058)$ Finally, the participants were asked 'if testing for chlamydial infection was offered, would you choose a urine test' and '... would you choose a vulval swab?' The women in this study were significantly more likely to choose testing by urine $-95.1 \%(98 / 103)$, than by vulval swab - 78.6\% (81/103) $(\mathrm{p}=0.001)$.

Table 3 shows the reasons why participants didn't like a test. Comments from the participants formed three themes. The first related to the non-invasive nature of both tests: 'A
Table 2 Reasons given by decliners $(n=49)$

\begin{tabular}{lc}
\hline Reason & $\begin{array}{l}\text { Decliners } \\
\mathrm{n}(\%)\end{array}$ \\
\hline I don't have the time & $17(34.7)$ \\
I have my period & $14(28.6)$ \\
Unnecessary as I'm not at risk & $10(20.4)$ \\
Didn't want to do a vulval swab & $8(16.3)$ \\
I would worry about a positive result & $5(10.2)$ \\
Not important to have done & $2(4.1)$ \\
Recently tested for Chlamydia & $1(2.0)$ \\
Don't like to take part in research & $1(2.0)$ \\
Too many tests & $1(2.0)$ \\
Didn't want to produce a sample of urine & 0 \\
\hline
\end{tabular}

lot more pleasant than previous methods' and 'Excellent, not embarrassing.' The second related to negative aspects of the vulval swab: 'Not sure if it (swab) was done properly', 'The swab was: difficult to break .... a bit awkward ....easy to drop.' The third related to positive aspects of vulval swabbing: 'Vulval swab was very easy and straightforward, less messy than a urine test', 'I thought it was better than having someone else to do it ', and 'The vulval swab was much easier to do'.

\section{Discussion}

This study found that opportunistic testing of young women for genito-urinary $C$. trachomatis infection using selfcollected vulval swabs assayed by LCR compared favourably with urine testing in terms of sensitivity and acceptability.

The study population was chosen to reflect those women who will be targeted if the CMO's Expert Advisory Group's recommendations are accepted. The refusal rate of almost one in three reflects the difficulties in encouraging asymptomatic young Scottish women to be screened. In contrast, an American study comparing self-sampled vulval swabs to clinician-sampled vulval swabs and endocervical samples assayed by polymerase chain reaction reported a decline rate of only $2 \% .^{18}$ Their population were likely to accept testing, however, as they were selected by having risk factors for sexually transmitted infection (STI) or had recently been diagnosed with $C$. trachomatis infection. Furthermore, American women have annual smears.

The importance of assessing why women withhold consent to participate in clinical trials has recently been highlighted in the pregnant population, highlighting issues of 'It could never happen to me', poor communication, and method of recruitment. ${ }^{19}$ These are all issues relevant to STIs.

It is encouraging that no demographic differences were found between those who participated and those who declined, and that two thirds of those who refused to participate stated a time factor or menstruation as the reason. One would hope that they would agree to screening at a subsequent visit. The aforementioned American study found that $43 \%$ and $36 \%$ of their women never used tampons or never looked at their own genitals, respectively. ${ }^{18}$ This

Table 3 Reasons for not liking vulval and urine tests

\begin{tabular}{lll}
\hline Reason & $\begin{array}{l}\text { Vulval swab } \\
\mathrm{n}(\%)\end{array}$ & $\begin{array}{l}\text { Urine } \\
\mathrm{n}(\%)\end{array}$ \\
\hline Embarrassing & $1(1.0)$ & 0 \\
Uncomfortable & $5(4.9)$ & 0 \\
Difficult to do & $4(3.9)$ & $2(1.9)$ \\
Time consuming & 0 & $1(1.0)$ \\
\hline
\end{tabular}


information was not collected from our women, so we are unable to confirm whether the $16 \%$ of those who declined to participate because of the vulval swab aspect represented those who are more introspective regarding their genitalia.

Of concern, however, were the $35 \%$ who felt that they did not need to be tested for $C$. trachomatis infection. Overall, knowledge of the infection and its sequelae in this group of women is known to be poor ${ }^{20}$ and targeted health education is urgently required so that individual risk is recognised.

Our definition of an infected patient has been used by other researchers. ${ }^{18,21-22}$ We defend our definition by acknowledging that there is now abundant evidence supporting superior sensitivity and specificity of LCR in comparison to older diagnostic tests. ${ }^{10,11,22}$ Specificity, however, is a concern with DNA amplification methods because even slight contamination can be potentiated by the amplification reaction. To increase specificity, retesting of the initially positive specimens was done. This left one woman with discrepant results. The MOMP LCR was chosen as the confirmatory test as it has been shown to have greater sensitivity compared to direct immunofluorescence, ${ }^{23}$ particularly with female urine. ${ }^{24}$ Furthermore, the MOMP assays were blinded, with four negative controls accurately confirmed. The results confirmed the validity of the positive vulval specimen in the patient with a negative urine.

With regard to comparative studies, specimens described as vaginal swabs relate to sampling from the same area. Hook et al ${ }^{25}$ compared patient-obtained vaginal swabs assayed by LCR to culture in a genito-urinary medicine population. A similar prevalence $(12.9 \%)$ and sensitivity $(91.8 \%)$ was found. Gray et $\mathrm{al}^{26}$ screened 373 rural Africans using paired self-collected vaginal swabs and urine. Prevalence was lower $(3.5 \%)$, but the two tests performed equally, identifying $15 / 17$ positive women. They also found a discordant rate of $1 \%$ but these samples were not re-tested.

Why would vulval swabs have an apparently higher sensitivity in this study? Female chlamydial infection may involve the cervix, urethra or both and one theory is that exfoliated cellular debris and organisms from both the infected cervix and urethra are present at the vaginal introitus. ${ }^{27}$ As most women are infected at the cervix, an area remote from the urethra, urine testing may miss some lower genital tract infections.

No studies, to our knowledge, have assessed patient acceptability of non-invasive testing for $C$. trachomatis infection. There was no significant difference found regarding preference for a particular test or specific recommendation to a female friend or relative. More women found the vulval swab 'embarrassing', 'uncomfortable' and 'difficult to do' than with urine testing, but the numbers were small. The finding that urine was significantly more likely to be chosen over vulval swabs was not surprising owing to its familiarity. However, vulval testing compared well, with almost $80 \%$ stating they would chose this method again. If not compared directly to urine, patient-collected swabs may have a comparable acceptability, but this is beyond the conclusions of this study.

Patient counselling, highlighting swabbing method, possibly using a model, could potentially eliminate the $9 \%$ who found the test uncomfortable or difficult to do. However, we acknowledge that those who are more introspective of their genital area may never feel comfortable with this method of screening.

The ideal diagnostic test for $C$. trachomatis infection would combine patient acceptability, ease of sampling and testing, high sensitivity and specificity, and competitive costs. The main limitations of endocervical specimens are that the speculum examination is uncomfortable, the procedure limits where the test can be performed, and the need for trained healthcare personnel increases costs. In comparison, by avoiding a speculum examination, noninvasive testing may increase a patient's willingness to undergo a screening test and provide the opportunity to expand screening to individuals who might not otherwise be offered or choose to undergo testing. Furthermore, it limits the need for skilled personnel, thereby decreasing costs, and may permit screening at locations where there would be difficulties in conducting pelvic examinations i.e. school, home, and mobile units. The only criticism of this type of approach has been the loss of the vaginal examination. We argue that those who are asymptomatic of pelvic complaints, those who do not require or have undergone cervical cytology, and those who screen negative for $C$. trachomatis infection, do not need a vaginal examination. In contrast, those with symptoms will by and large accept examination; those requiring a smear should undergo endocervical testing, and those positive for C. trachomatis infection should proceed to examination and a complete STI screen.

\section{Conclusion}

This study found that opportunistic testing for genitourinary $C$. trachomatis infection on women using LCR assay of patient-collected vulval swabs was as sensitive as LCR of urine, with high acceptability. Compared to urine testing, advantages in terms of specimen provision, transport, and processing should encourage more widespread use of this approach. Vulval swabbing must not be over-shadowed by the familiarity of urine as, ultimately, it may be the most acceptable screening method to both patients and health professionals. Further research is required to assess the acceptability of this method alone, the effects of pregnancy and menstrual blood on non-invasive testing, and why women decline screening.

\section{Acknowledgements}

We wish to thank all the women who volunteered to be tested. We thank Mrs J Skinner and Mrs L Ford for excellent technical assistance and Abbott Diagnostics, UK for performing the LCR-MOMP assays. We are grateful for the statistical assistance provided by Ann Fitzmaurice.

Statements on funding and competing interests

Funding. None

Competing interests. None

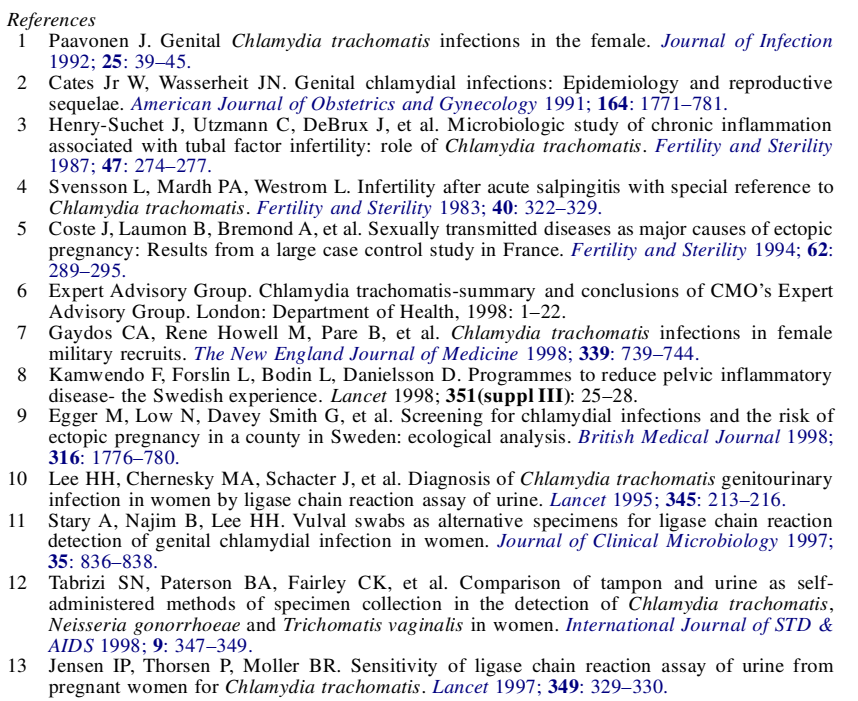
ciated with tubal factor infertility: role of Chlamydia trachomatis. Fertility and Sterility

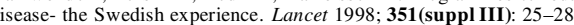

Eow N, Davey Smith G, et al. Screening for chlamyditi infec

Lee HH, Chernesky MA, Schacter J, et al. Diagnosis of Chlamydia trachomatis genitourinary infection in women by ligase chain reaction assay of urine. Lancet 1995; 345: 213-216.

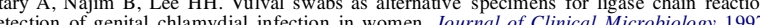
Paterson BA, Fairley $\mathrm{CK}$, et al. Comparison of tampon and urine as selfadministered methods of specimen collection in the detection of Chlamydia trachomatis, AIDS 1998; 9: $347-349$ 
14 Thomas BJ, Pierpoint T, Taylor-Robinson D, Renton AM. Sensitivity of ligase chain reaction for detecting Chlamydia trachomatis in vaginal swabs from women who are infected at other sites. Sexually Transmitted Infections 1998; 74: 140-141.

15 Owen Caul E, Horner PJ, Leece J, et al. Population-based screening programmes for Chlamydia trachomatis. Lancet 1997; 349: 1070-1071.

16 Ostergaard L, Moller JK, Andersen B, et al. Diagnosis of urogenital Chlamydia trachomatis infection in women based on mailed samples obtained at home: multipractice comparative study. British Medical Journal 1996; 313: 1186-189.

17 Griner PF, Mayewski RJ, Mushlin AI, et al. Selection and interpretation of diagnostic tests and procedures. Annals of Internal Medicine 1981; 94: 553-585.

列 dectinna K. Tunna K. With pregnat women. British Journal of Obstetrics and Gynaecology 1999; 106: 892-897. Macmillan S, Walker R, Oloto E, et al. Ignorance about Chlamydia among sexually active women- a two centre study. Human Reproduction 1999; 14: 1131-135.

1 Davis JD, Riley PK, Peters CW, et al. A comparison of ligase chain reaction to polymerase chain reaction in the detection of Chlamydia trachomatis endocervical specimens. Infectious Diseases in Obstetrics \& Gynecology 1998; 6: 57-60.

22 Bassiri M, Hu HY, Domeika MA, et al. Detection of Chlamydia trachomatis in urine specimens from women by ligase chain reaction. Journal of Clinical Microbiology 1995; 33: $898-900$

23 Schachter J, Moncada J, Whidden R, et al. Noninvasive tests for diagnosis of Chlamydia trachomatis infection: application of ligase chain reaction to first-catch urine specimens of women. The Journal of Infectious Diseases 1995; 172: 1411-414.

24 Chernesky $\mathrm{M}$, Le H, Jang D, et al. Detection of female Chlamydia trachomatis infection of the lower genital tract by testing first-void urine (FVU) in ligase chain reaction (LCR). Sex

25 Hook III EW, Smith $\mathrm{K}$, Mullen $\mathrm{C}$, et al. Diagnosis of genito-urinary Chlamydia trachomatis infections by using the ligase chain reaction on patient-obtained vaginal swabs. Journal of .

(aird Chlamydia trachomatis infection. Sexually Transmitted Diseases 1998; 25: 450

7 Wiesenfield $\mathrm{HC}$, Heine RP, Rideout A, et al. The vaginal introitus: a novel site for Chlamydia trachomatis testing in women. American Journal of Obstetrics and Gynecology 1996; 174: $1542-546$.

$\underline{\underline{T}}$

$c$ 